\title{
13
}

\section{Taking lessons from policy theory into practice}

\author{
Paul Cairney
}

\section{Introduction}

Policy theorists and policy practitioners could learn from each other continuously if they could communicate more frequently and effectively. They could build on some promising developments, which suggest that there is scope for mutual learning between policy theorists and practitioners (see Threlfall \& Althaus this volume, Chapter 2). Academics draw general and relatively abstract conclusions from multiple cases, and their work has some impact on practitioner experience (such as via early career development training). Practitioners draw conclusions from rich descriptions of direct experience in specific cases, and these experiences can often inform policy studies (such as via elite interviews). How can we bring together their insights and use a language that we all understand and appreciate?

This chapter focuses on the role of policy theory in that conversation. Many policy theories could be valuable to policy practitioners if communicated more effectively (or, as Ayres [this volume, Chapter 8] describes, if they use them directly to describe their own task). In other words, the implications have to be relevant and feasible to practitioners, the language needs to be clear to a wider audience and the presentation needs to compete well with other models (such as the classic policy cycle). To maximise their impact, we need to turn two potential obstacles into advantages. 
First, policy theories provide relatively abstract insights, producing general conclusions that are not immediately obvious to practitioners if they seek more concrete advice. However, we can use their broad insights to identify the extent to which individual practitioner experiences are specific to their own context or part of a 'universal' experience. In particular, some general stories of policymaking have profound implications about the limits to policymaker attention and the lack of government control over policy processes.

Second, policy theories focus primarily on explaining policymaking, and few studies offer practical guidance. As such, they are often ignored in favour of less accurate but more user-friendly models. Further, guidance from policy theory tends to appeal to policymakers' sense of pragmatism (about adapting to the limits to their powers) without accounting for key pressures, such as the electoral environment in which all policy practitioners operate, and in which elected policymakers in government have to project power. However, we can at least use theories to identify key ethical and practical issues, partly to assess the value of simpler and allegedly more practical models.

No single account of policy theories can cover their depth and variety. Rather, I outline one story, based on key elements of many policy theories. Its main message is that policymakers can only pay attention to a small proportion of their responsibilities, and they engage in a policy process over which they have limited knowledge and even less control. I use this story to identify key implications for two main reference points in academic-practitioner discussions:

1. to question the descriptive and practical value of the 'policy cycle' image of policymaking via a series of stages

2. to reject the slogan 'evidence-based policymaking' as a useful or realistic way to describe governance.

I conclude by describing some examples-from personal experienceof how academics and practitioners can engage with each other to consider the role of evidence and governance in a political process. 


\section{Policy theory: A story of policymaker psychology and policymaking complexity}

Some models are popular because they provide a low-jargon message about how policymaking could, and perhaps should, be made (Cairney 2015). More sophisticated policy theories may be more accurate, and potentially more useful, but 'they are also less accessible to researchers seeking conceptual clarity and to practitioners looking for useful knowledge of policymaking' (Cairney, Heikkila \& Wood 2019, p. 1). Therefore, my first task is to project the sense that we can synthesise key policy theory insights to produce a low-jargon story of policymaking with practical value.

Put most simply, this story is that policymakers engage in a policy process over which they have limited knowledge and even less control. If so, we need to give up on models that project simplicity and central control (such as the policy cycle) and be clear on what the meanings of popular aims-such as 'evidence-based policymaking' — are, or could be, in practice.

This story is based on two factors (see Cairney 2020, ch. 13). The first relates to 'bounded rationality' (Simon 1976) and policymaker psychology. The world contains an almost infinite amount of information, but humans have finite cognitive abilities. By necessity, they must combine cognition and emotion to limit information searches and make choices (Cairney \& Kwiatkowski 2017; Gigerenzer 2001, pp. 37-8; Kahneman 2012, p. 20). We can spin this process negatively, with reference to the 'cognitive biases' that prompt humans to make suboptimal decisions (such as by engaging only with information they already understand or being vulnerable to 'groupthink'), or positively to describe 'fast and frugal heuristics' and the human ability to make efficient choices based on emotion, values and simple strategies such as trial and error (Gigerenzer 2001, pp. 37-8).

In policy studies, bounded rationality translates into a variety of assumptions or expectations, but a key story is that policymakers can only pay attention to a tiny proportion of their responsibilities, and policymaking organisations struggle to process all policy-relevant information. They must prioritise some issues and information and ignore the rest (Baumgartner, Jones \& Mortensen 2018). They do so in a variety of ways: drawing on fundamental beliefs such as ideologies, paradigms, hegemons and core beliefs; relying on organisational rules; 
listening only to their allies; engaging in trial and error strategies; making quick emotional judgements in relation to social stereotypes; and telling or following simple stories that limit attention to a small number of a) preferred ways to frame policy problems and b) politically feasible ways to solve them (Cairney 2020; Jenkins-Smith et al. 2018; Ostrom 2007; Schneider et al. 2014; Shanahan et al. 2018).

The second factor relates to complex policymaking environments (see also Geyer \& Cairney 2015, on 'complex systems'). We can describe this environment with reference to five constituent parts, summarised in Table 13.1, and accompanied by a possible moral for each factor. Combined, the story is that policymakers struggle to understand (far less control) an environment in which there are many actors spread across many venues, each with their own rules, ideas, networks, and responses to socioeconomic conditions and events.

Table 13.1. Bounded rationality in a complex policymaking environment.

\begin{tabular}{|l|l|l|}
\hline Concept & Academic summary of each concept & One moral of the story \\
\hline $\begin{array}{l}\text { Bounded } \\
\text { rationality }\end{array}$ & $\begin{array}{l}\text { Policymakers combine cognition and emotion } \\
\text { to limit information searches and make choices. }\end{array}$ & $\begin{array}{l}\text { Policymakers cannot } \\
\text { process all policy- } \\
\text { relevant information. }\end{array}$ \\
\hline Actors & $\begin{array}{l}\text { There are many actors -including policymakers } \\
\text { and influencers - spread across many types } \\
\text { of policymaking venues (venues are sources } \\
\text { of authoritative choice). }\end{array}$ & $\begin{array}{l}\text { Power is not } \\
\text { concentrated in a single } \\
\text { centre of government. }\end{array}$ \\
\hline Institutions & $\begin{array}{l}\text { Each venue contains its own 'standard operating } \\
\text { procedures' or 'rules of the game'. Some are } \\
\text { formal, written and understood easily. Others are } \\
\text { informal, unwritten and often taken for granted } \\
\text { or communicated through socialisation. }\end{array}$ & $\begin{array}{l}\text { There is no single } \\
\text { rule book. }\end{array}$ \\
\hline Networks & $\begin{array}{l}\text { Each venue can produce its own networks of } \\
\text { policymakers and influencers, and the lines } \\
\text { between formal responsibility and informal } \\
\text { influence are blurry. }\end{array}$ & $\begin{array}{l}\text { There is no singular } \\
\text { process of consultation } \\
\text { or simple way to } \\
\text { coordinate action. }\end{array}$ \\
\hline Ideas & $\begin{array}{l}\text { Actors in each venue draw on a different set of } \\
\text { core ideas or beliefs about the nature of policy } \\
\text { problems and the acceptable range of solutions. }\end{array}$ & $\begin{array}{l}\text { A language in good } \\
\text { currency in one venue } \\
\text { may have no value } \\
\text { in another. }\end{array}$ \\
\hline $\begin{array}{l}\text { policy problems. Routine and non-routine } \\
\text { policymakents help to set the policy agenda and } \\
\text { influence the resources available to actors. }\end{array}$ & $\begin{array}{l}\text { Policymakers do not } \\
\text { control key events } \\
\text { and socioeconomic } \\
\text { conditions. }\end{array}$ \\
\hline
\end{tabular}

Source: Adapted from Cairney (2020), John (2003, p. 495), Heikkila and Cairney (2018), and Ostrom (2007). 
Lindblom's (1959, 1979) incrementalism is a classic way to describe how policymakers address bounded rationality in such policymaking environments: they adopt pragmatic ways to a) gather and use information, b) engage in strategic analysis and c) negotiate political settlements that do not depart radically from the status quo. In other words, policy change is incremental because people see the benefits of only studying in-depth the changes that would be technically feasible, in relation to available resources, and politically feasible, in relation to current policy and the balance of power. Further, Lindblom's phrase 'muddling through' is popular among many practitioners, perhaps because it sums up the idea that their options are limited but they are still making key choices about how to deal with their environment. 'Muddling through' highlights pragmatism and realism without giving up on the idea of some degree of central direction. Similarly, 'disjointed incrementalism' describes many pragmatic strategies that will be familiar to practitioners, including the intensive analysis of a small number of options (rather than a heroic sweep of all possible choices) and trial and error learning.

Yet, this interpretation of Lindblom's account is potentially misleading in two main ways. First, 'punctuated equilibrium theory' (PET) shows that policymaking systems actually produce 'hyperincremental' and non-incremental policy change, or the combination of long periods of policymaking stability and bursts of instability (Baumgartner, Jones \& Mortensen 2018). Second, PET is one of many approaches that highlight the lack of policymaker awareness of the processes over which they ostensibly have control. PET studies highlight the role of 'disproportionate information processing', in which policymakers and organisations devote minimal attention to most issues (and maximal attention to some), or their attention lurches from one issue to another without a proportionate shift in information on the size of a problem. Policymakers set goals but 'they are not generally effective in judging the connections between [their] goals and the complex reality they face' (Jones \& Thomas 2017, p. 49). All policy actors communicate their particular expertise within a much larger system of which they have almost no knowledge (Sloman $\&$ Fernbach 2017). In any situation, 'most members of the system are not paying attention to most issues most of the time' (Baumgartner 2017, p. 72). 
This scarcity of attention and environmental awareness helps explain why the 'centre' will always be subject to limits to their coordinative capacity (see Cairney 2020):

- Limited choice. Policymakers inherit organisations, rules and choices. Most 'new' choice is a revision of the old (Hogwood \& Peters 1983; Rose 1990).

- Limited attention. Policymakers must ignore almost all of the policy problems for which they are formally responsible. They pay attention to some, and delegate most responsibility to civil servants. Bureaucrats rely on other actors for information and advice, and they build relationships on trust and information exchange.

- Limited central control. Policy may appear to be made at the 'top' or in the 'centre', but in practice policymaking responsibility is spread across many levels and types of government (many 'centres'). Policy outcomes appear to 'emerge' locally despite central government attempts to control their fate. This diffusion of power is partly through choice (such as in federal systems), but also borne of necessity (Cairney, Heikkila \& Wood 2019).

- Limited policy change. Most policy change is minor, made and influenced by actors who interpret new evidence through the lens of their beliefs. Well-established beliefs limit the opportunities of new solutions. New solutions succeed only during brief and infrequent windows of opportunity.

This description of policymaking must inform prescription: seeking policymaking solutions based on the idea of an all-knowing and allpowerful centre is like trying to fly unaided rather than designing and using a plane (Lindblom 1964). One frequent source of advice is via complexity theory, in which scholars generally encourage policymakers to accept and describe their limits: accept routine error, reduce short-term performance management, engage more in trial and error, and 'let go' to allow local actors the flexibility to adapt and respond to their context (Cairney 2012). In other words, to give up on the idea of being 'able to manipulate systems in a god-like way', in favour of coordinating the action of many autonomous actors within a policymaking system (Stewart \& Ayres 2001, pp. 80, 87). 


\section{Implications for the policy cycle}

This story of limited awareness and control is straightforward to tell but not to sell. Communication is only one part of the problem. The other is that it does not help policymakers tell a story about what governments are elected to do. It is a particular problem for governments operating in the Westminster tradition, who need to balance two inevitable but competing tensions: to engage in pragmatic policymaking and maintain an image of governing competence built on central control (Cairney 2015). Central government policymakers may accept the descriptive accuracy of policy theories emphasising limited central control, but not the recommendation that they should let go, share power and acknowledge their limits to the public.

In that context, the cycle metaphor appears to endure because it provides a way to project a particular form of policymaking to the public: you know how we make policy, and that we are in charge, so you know who to hold to account (see also Mercer [this volume, Chapter 3] and Wanna [this volume, Chapter 4] on the cycle as an aid to new public servants who learn on-the-job and in 'in-service' training; and Maurer [this volume, Chapter 12] on its role, within government, in boosting confidence, providing a common language, and setting cross-departmental expectations). It also provides a simple model of policymaking with stages that map onto important policymaking functions: identify and define problems that require government attention; identify the costs and benefits of solutions; legitimise your choice of solution; ensure sufficient resources for implementation; establish if the policy was successful; and decide if the policy should be continued, modified or discontinued.

Yet, if we take seriously the policy theory story, it is difficult to conclude that the cycle metaphor can actually endure in a meaningful or practical sense. At some point, it becomes too difficult to project the sense that policy is made from the centre, via a series of orderly stages, when this projection is so clearly inaccurate. For example, one of the formerly strongest proponents of this image-the European Commissionnow describes a far messier reality (Topp et al. 2018). If so, the idea of centralised policymaking gives way to a focus on 'multi-level governance', 'polycentric governance' or 'multi-centric policymaking' to describe the need to accept the limited coordinative capacity at the 'centre' and explore ways to establish governing legitimacy when many policy practitioners 
have a clear role (Cairney, Heikkila \& Wood 2019). Central government policymakers often decide to share power, and often seem to like the idea of delegating responsibility to other actors while finding pragmatic ways to legitimise actions by unelected bodies (John 1998, p. 29; Jordan \& Richardson 1987, p. 233). However, modern policy theories suggest that key forms of power sharing are necessary and inevitable, rather than in their gift (Cairney, Heikkila \& Wood 2019).

If we accept this story, the only enduring advantage to the policy cycle image relates to the functions associated with its stages, since they provide a way for civil servants to manage their work and turn elected government aims into reality (Althaus, Bridgman \& Davis 2013; cf. Ritchie [this volume, Chapter 10] whose Policy Enterprise Model situates the cycle within a wider policymaking and cultural context). Yet, the policy theory story helps us reject the idea that we can use such an artificial model to plan civil service work. The usual image of a policy cycle is of a single cycle, to represent either a) a single process overseen by a small group of policymakers and analysts, who are in possession of the facts and control of the policy process, carrying out their aims through a series of stages; or, more realistically, b) a huge set of policy cycles that connect with each other in messy and unpredictable ways. Picture a kaleidoscope or Spirograph rather than a single circle. If so, what could be the point of 101 policymakers each being at the centre of their own policy cycles if they do not engage with the policy processes of their colleagues? What happens in cross-cutting issues when the cycles of one unit are out of sync with another?

In that context, perhaps the most we can expect of the policy cycle's stages is to treat them as a checklist of functions to carry out at some point (i.e. define problems, identify solutions, legitimise your work and evaluate policy processes) without expecting to be able to apply them rigidly or in order, and while remaining cognisant of the bigger picture in which any such planning would take place (cf. Edwards's [this volume, Chapter 7] discussion of 'covering all stages in the policy process, although not necessarily in any order'). If so, the policy theory story has much to offer the checklist, including:

- find out where the action is (establish the policymakers and influencers with whom to engage)

- form networks and seek allies (establish whose support you need, and how to get it) 
- learn the language of debate and rules of the game in multiple venues (establish how best to engage with multiple policy actors in and out of government).

This kind of 'intelligent policymaking' (Sanderson 2009), built on awareness of your position in a complex system over which you have no control, seems like a more useful focus of training than a simple set of functions built on a too simple understanding of policy processes (see also Koski \& Workman 2018 on ways for governments to process information more effectively).

\section{Implications for 'evidence-based policymaking'}

This shift of focus should also have a major effect on the discussions people have about 'evidence-based policymaking' (EBPM). One part of the problem with the idea of EBPM is that many of its advocates describe it from the perspective of actors who are primarily outside of government, looking in. As such, they compare their unrealistic expectations for policymaking (based on simple models like the policy cycle) with the far less rewarding processes that they actually experience. Oliver, Lorenc and Innvær's (2014) systematic review finds that a) few scholars outside of policy studies rely on policy concepts and b) almost all of those scholars engage primarily with the policy cycle. If they seek to engage with policymakers, who also project this sense of centralised and orderly policymaking, they will expect to find several opportunities to present evidence to help to define the nature and urgency of a policy problem, weigh up the costs and benefits of solutions, and evaluate the chosen solution before a debate on whether or not to continue.

This fiction of order and control provides a false sense of security to evidence advocates, who will soon be disappointed with their engagement. If so, they may refer primarily to the alleged problems with politicians (who do not listen to or understand evidence, or do not have the political will to do something with it), rather than their own lack of knowledge of complex policymaking environments, to explain their limited impact. It may warp their views on why policy practitioners seek and use a wide variety of sources of information rather than simply trying to base policy on narrowly defined scientific evidence (see e.g. Gilding's [this volume, Chapter 11] description of triple bottom line assessment). 
In contrast, a policy theory story allows us to think about three main processes to which all policy advocates must respond:

1. Policy practitioners necessarily have a broader view on what counts as good evidence, since they need to identify the policy relevance of information, and engage in some process of deliberation to manage societal beliefs or preferences. In other words, they are not simply technocrats looking for technically feasible solutions.

2. They have to ignore almost all information, almost all of the time, and seek efficient ways to manage and use evidence.

3. They do not fully understand or control the process in which they seek to use evidence. Rather, they are part of a large and complex policymaking environment in which many policy actors have influence. If things appear to go wrong, we should not assume it is their fault.

This story allows policy actors to engage with a policy process that exists, rather than an orderly and predictable process that they would like to see. Instead of seeking to supply evidence at formally defined stages, they would instead develop a series of strategies to deal with uncertainty:

- There are many policy practitioners and influencers spread across government, so find out where the action is, or the key venues in which people are making authoritative decisions.

- Each venue has its own 'institutions'-the formal and written, or informal and unwritten rules of policymaking - so learn the rules of each venue in which you engage.

- Each venue is guided by a fundamental set of ideas - paradigms, core beliefs, monopolies of understanding — so learn that language and its implications.

- Each venue has its own networks - the relationships between policy practitioners and influencers - so build trust and form alliances within networks (or venue shop, to find a more sympathetic audience).

- Policymaking attention is often driven by changes in socioeconomic factors or routine/non-routine events, so be prepared to exploit the 'windows of opportunity' to present your solution during heightened attention to a policy problem. 
It prompts actors to consider how far they are willing to go to pursue EBPM, when they know that the evidence will not speak for itself. For example, are they willing to emulate interest groups to frame issues, tell stories, close off debate, and/or exploit social stereotypes to gain the attention and support of policymakers (see Cairney 2018a)? It also allows actors to manage their expectations, since:

Policy studies recommend investing your time over the long term-to build up alliances, trust in the messenger, knowledge of the system, and to seek 'windows of opportunity' for policy change- but offer no assurances that any of this investment will ever pay off. (Cairney \& Oliver 2019, p. 8)

Further, even if successful, evidence advocates may find it difficult to pinpoint and measure their own impact.

\section{Implications for practitioner-academic exchange}

If academics and practitioners accept this policy theory story, how can they engage with each other to consider the role of evidence and governance in a political process over which no one has full control and many actors need to find ways to cooperate effectively? In this section, I describe some examples of possible responses, based on work I have done with practitioners such as civil servants.

First, policy theories can be used to lead small group discussions during executive training. For example, I have found that civil servants in the UK and Scottish (central) governments tend to agree that 1) the policy cycle is a useful starting point to describe what does not happen, and 2 ) we need some way to describe a far messier and complex policymaking process. In other words, the cycle is more of an ideal type to compare with reality than an ideal state to which to aspire. If so, it prompts a period of reflection, in which civil servants discuss how to operate within a more complex process, to balance being pragmatic about their limited role with the need to help ministers project a sense of central control (Cairney 2015, pp. 33-5). These discussions tend to promote critical thinking, or 'intelligent policymaking' (Sanderson 2009), and civil service networking, rather than blueprints or specific models of behaviour based on policy theories. 
Second, policy theories inform wider strategies for policymaking organisations. For example, with the European Commission's Joint Research Centre, I co-authored a discussion of eight key skills or functions for an organisation seeking to bring together the supply and demand of policy-relevant knowledge (Topp et al. 2018, p. 1):

(1) research synthesis, to generate 'state of the art' knowledge on a policy problem; (2) management of expert communities, to maximise collaboration; (3) understanding policymaking, to know when and how to present evidence; (4) interpersonal skills, to focus on relationships and interaction; (5) engagement, to include citizens and stakeholders; (6) effective communication of knowledge; (7) monitoring and evaluation, to identify the impact of evidence on policy; and (8) policy advice, to know how to present knowledge effectively and ethically.

This agenda is particularly relevant to academics, since its main messages are about how to produce policy-relevant knowledge, increase its perceived legitimacy (as part of wider scientific or stakeholder engagement), operate effectively in a policy process and provide policy advice in political settings. Further, if policy practitioners accept a messy and uncontrollable policy process (rather than an orderly cycle) as a starting point, it prompts them to think in new ways about how to gather policy-relevant knowledge, engage more widely with stakeholders and reflect on the limits to their policy impact.

Third, policy theories can help us think through the ways in which we discuss EBPM in relation to governance (as described in the Policy Project's (2018) write-up of our workshop with civil servants from the New Zealand government). Some of this discussion is so straightforward that a reference to policy theory jargon would get in the way. For example, there are common descriptions of the gap between academic and policymaker cultures based on factors such as technical languages, timescales, professional incentives, relative comfort with uncertainty, and assessments of scientific evidence in relation to other forms of policyrelevant information and values or beliefs. In that context, I suggest to civil servants that many academics might be interested in more engagement, but might be put off by the overwhelming scale of their task, and-even if they remained undeterred-would face some practical obstacles: 
1. They may not know where to start: who should they contact to start making connections with policymakers?

2. The incentives and rewards for engagement may not be clear. The UK's 'impact' agenda has changed things, but not to the extent that any engagement is good engagement. Researchers need to tell a convincing story that they made an impact on policy/policymakers with their published research, so there is a notional tipping point of engagement in which it reaches a scale that makes it worth doing.

3. The costs are significant. For example, any time spent doing engagement is time away from writing grant proposals and journal articles (in other words, the outputs that still make careers).

4. The rewards and costs are not spread evenly. Put most simply, white male professors may have the most opportunities and face the fewest penalties for engagement in policymaking and social media (Cairney \& Oliver 2019; Oliver \& Cairney 2019; Savigny 2019). Or, the opportunities and rewards may vary markedly by discipline. In some, engagement is routine. In others, it is time away from core work.

Therefore, civil servants should provide clarity on what they expect from academics, when they need information and what they can offer in return. They should also show some flexibility with deadlines. Better still, they should engage continuously with academics to help form networks and identify the right people needed at the right time.

However, there is also a clear role for policy theories in thinking through the relationship between evidence use and governance. Table 13.2 provides one case study to identify consistent models of evidence use when we combine political choices about what counts as good evidence and what counts as 'good policymaking' when we assume complexity rather than control (Cairney 2016, 2017, 2018b). For example, one aim is to use evidence of success in one area and 'scale up' the program to a wider area. There are three approaches in good currency: use evidence from randomised control trials to diffuse the same model; use storytelling to describe experiences, assuming that each new intervention takes place under new conditions, and explicitly rejecting uniformity; or train practitioners to experiment with policy solutions based on promising but incomplete evidence. 
In this case, the policy theory story may help make one approach more competitive and defendable than we would otherwise expect. If we were to make the problematic assumption that some policymakers could exert their power to roll out the same model uniformly, and that the model has a uniform effect, then approach 1 -driven primarily by randomised control trials (RCTs) - would be relatively attractive. In contrast, if we assume the absence of central control, and that the same policy introduced in two places can have very different effects, then approach 2-driven by experiential knowledge, storytelling and governance principles (such as localism and respect for service-user design) — becomes more competitive. So too does approach 3 , in which the idea is that central governments give practitioners 'on the ground' the freedom to experiment and learn what works in their experience.

Table 13.2. How should you combine evidence and governance to 'scale up' policy?

\begin{tabular}{|l|l|l|l|}
\hline & $\begin{array}{l}\text { 1. Implementation } \\
\text { science }\end{array}$ & 2. Storytelling & $\begin{array}{l}\text { 3. Improvement } \\
\text { method }\end{array}$ \\
\hline $\begin{array}{l}\text { How should you } \\
\text { gather evidence? }\end{array}$ & Hierarchy and RCTs & $\begin{array}{l}\text { Practitioner } \\
\text { knowledge } \\
\text { Service-user feedback }\end{array}$ & $\begin{array}{l}\text { Evidence and } \\
\text { 'experimentation' }\end{array}$ \\
\hline $\begin{array}{l}\text { How should you } \\
\text { 'scale up' from } \\
\text { best practice? }\end{array}$ & $\begin{array}{l}\text { Uniform model } \\
\text { Fidelity to the model }\end{array}$ & $\begin{array}{l}\text { Tell stories, invite } \\
\text { people to learn }\end{array}$ & $\begin{array}{l}\text { If it is working, } \\
\text { keep doing it }\end{array}$ \\
\hline $\begin{array}{l}\text { What aim should } \\
\text { you prioritise? }\end{array}$ & $\begin{array}{l}\text { Evidence of active } \\
\text { ingredient of } \\
\text { a dosage }\end{array}$ & Governance principles & $\begin{array}{l}\text { Training and } \\
\text { feedback }\end{array}$ \\
\hline
\end{tabular}

\section{Conclusion}

Most policy theories help explain policymaking rather than seek to promote what should, or predict what will, happen. As such, on their own, they do not provide direct advice on how to act, or try to set the direction of travel, within policy processes. Yet, they provide some useful pointers for actors seeking influence-frame issues to make them policy relevant, find out where the action is, learn the rules and language, find allies—and explain why these actions matter. Different theories also help explain to civil servants the patterns they may see while in government. For example, elected policymakers can ignore an issue or evidence for long periods, then suddenly pay high attention and demand a solution almost as soon as they describe a problem. Or, the same evidence-informed story may generate 
full support from one coalition but energetic opposition from another. In some cases, we know who will support or oppose a story; in others, they reflect an identity, or set of beliefs, that is difficult to anticipate.

Further, we can use policy theories to generate stories of policy processes with profound relevance to practitioners. Put most simply, they encourage us to dispense with the imagery of order and government control associated with models such as the policy cycle. Instead, policymakers can only pay attention to a small proportion of their responsibilities, and they engage in a policy process over which they have limited knowledge and even less control. If we accept this story, we accept that practitioners need new ways to think about old ways of doing things. The policy cycle's functions may remain relevant, but as part of a kaleidoscope of activity in which problem definition and solution generation is part of a far larger and more collaborative process, rather than a self-contained cycle. It often makes little sense to evaluate policy as if implementation could be achieved from the top down. 'The evidence' matters, but the complex nature of the policy process has a major influence on what evidence counts.

In that sense, stories from policy theory primarily provide a lens through which to understand all forms of practical advice, often as a way of thinking more than a blueprint for action. However, they also help set a new agenda to consider how policy should be made. There comes a point when models such as the policy cycle become so unrealistic as to provide little normative guidance. If practitioners begin with this mindset, they can consider more realistic ways in which to juggle the need to be pragmatic and foster accountability in political systems.

\section{References}

Althaus, C, Bridgman, P \& Davis, G 2013, The Australian policy handbook: A practical guide to the policy-making process, 5th edn, Allen \& Unwin, Sydney, NSW.

Baumgartner, F 2017, 'Endogenous disjoint change', Cognitive Systems Research, vol. 44, pp. 69-73. doi.org/10.1016/j.cogsys.2017.04.001.

Baumgartner, F, Jones, B \& Mortensen, P 2018, 'Punctuated equilibrium theory', in C Weible \& P Sabatier (eds), Theories of the policy process, 4th edn, Westview, Chicago, IL, doi.org/10.1016/j.cogsys.2017.04.001. 
Cairney, P 2012, 'Complexity theory in political science and public policy', Political Studies Review, vol. 10, no. 3, pp. 346-58, doi.org/10.1111/j.14789302.2012.00270.x.

Cairney, P 2015, 'How can policy theory have an impact on policy making?', Teaching Public Administration, vol. 33, no. 1, pp. 22-39, doi.org/10.1177/ 0144739414532284.

Cairney, P 2016, The politics of evidence-based policymaking, Palgrave Pivot, London, UK.

Cairney, P 2017, 'Evidence-based best practice is more political than it looks: A case study of the "Scottish approach", Evidence and Policy, vol. 13, no. 3, pp. 499-515, doi.org/10.1332/174426416X14609261565901.

Cairney, P 2018a, 'How far should you go to privilege evidence?', Paul Cairney: Politics and Public Policy, viewed 11 January 2020, paulcairney.wordpress. com/2018/07/20/how-far-should-you-go-to-privilege-evidence-2-policytheories-scenarios-and-ethical-dilemmas/.

Cairney, P 2018b, 'Teaching evidence based policy to fly: How to deal with the politics of policy learning and transfer', Paul Cairney: Politics and Public Policy, viewed 11 January 2020, paulcairney.wordpress.com/2018/10/11/teachingevidence-based-policy-to-fly-how-to-deal-with-the-politics-of-policy-learningand-transfer/.

Cairney, P 2020, Understanding public policy, 2nd edn, Palgrave, London, UK.

Cairney, P, Heikkila, T \& Wood, M 2019, Making policy in a complex world, Cambridge University Press, Cambridge, UK, doi.org/10.1017/ 9781108679053 .

Cairney, P \& Kwiatkowski, R 2017, 'How to communicate effectively with policymakers: Combine insights from psychology and policy studies', Palgrave Communications, vol. 3, no. 37, viewed 11 January 2020, www.nature.com/ articles/s41599-017-0046-8, doi.org/10.1057/s41599-017-0046-8.

Cairney, P \& Oliver, K 2019, 'How should academics engage in policymaking to achieve impact?' Political Studies Review, special issue, vol. 18, no. 2, pp. 1-17, doi.org/10.1177/1478929918807714.

Geyer, R \& Cairney, P (eds) 2015, Handbook on complexity and public policy, Edward Elgar, Cheltenham, UK, doi.org/10.4337/9781782549529.

Gigerenzer, G 2001, 'The adaptive toolbox', in G Gigerenzer \& R Selton (eds), Bounded rationality: The adaptive toolbox, MIT Press, Cambridge, MA, doi.org/ 10.7551/mitpress/1654.001.0001. 
Heikkila, T \& Cairney, P 2018, 'Comparison of theories of the policy process', in C Weible \& P Sabatier (eds), Theories of the policy process, 4th edn, Westview, Chicago, IL.

Hogwood, B \& Peters, BG 1983, Policy dynamics, St Martin's Press, New York, NY.

Jenkins-Smith, H, Nohrstedt, D, Weible, C \& Ingold, K 2018, 'The advocacy coalition framework: An overview of the research program', in C Weible \& P Sabatier (eds), Theories of the policy process, 4th edn, Westview, Chicago, IL.

John, P 1998, Analysing public policy, Continuum, London, UK.

John, P 2003, 'Is there life after policy streams, advocacy coalitions, and punctuations: Using evolutionary theory to explain policy change?' Policy Studies Journal, vol. 31, no. 4, pp. 481-98, doi.org/10.1111/1541-0072.00039.

Jones, B \& Thomas, H 2017, 'The cognitive underpinnings of policy process studies', Cognitive Systems Research, vol. 45, pp. 48-51, doi.org/10.1016/ j.cogsys.2017.04.003.

Jordan, AG \& Richardson, JJ 1987, British politics and the policy process, Allen \& Unwin, London, UK.

Kahneman, D 2012, Thinking fast and slow, Penguin, London, UK.

Koski, C \& Workman, S 2018, 'Drawing practical lessons from punctuated equilibrium theory', Policy and Politics, vol. 46, no. 2, pp. 293-308, doi.org/ $10.1332 / 030557318 X 15230061413778$.

Lindblom, C 1959, 'The science of muddling through', Public Administration Review, vol. 19, no. 2, pp. 79-88, doi.org/10.2307/973677.

Lindblom, C 1964, 'Contexts for change and strategy: A reply', Public Administration Review, vol. 24, no. 3, pp. 157-8, doi.org/10.2307/973641.

Lindblom, C 1979, 'Still muddling, not yet through', Public Administration Review, vol. 39, no. 6, pp. 517-26, doi.org/10.2307/976178.

Oliver, K \& Cairney, P 2019, 'The dos and don'ts of influencing policy: A systematic review of advice to academics', Palgrave Communications, vol. 5, no. 21, viewed 11 January 2020, www.nature.com/articles/s41599-019-0232-y, doi.org/10.1057/s41599-019-0232-y.

Oliver, K, Lorenc, T \& Innvær, S 2014, 'New directions in evidence-based policy research: A critical analysis of the literature', Health Research Policy and Systems, vol. 12, no. 34, doi.org/10.1186/1478-4505-12-34. 
Ostrom, E 2007, 'Institutional rational choice', in P Sabatier (ed.), Theories of the policy process, 2nd edn, Westview Press, Cambridge, MA.

Policy Project 2018, 'Maximising collaboration between public servants and academics in evidence-based policy making', viewed 11 January 2020, paul cairney.files.wordpress.com/2018/10/paul-cairney-roundtable-conversationtracker.pdf.

Rose, R 1990, 'Inheritance before choice in public policy', Journal of Theoretical Politics, vol. 2, no. 3, pp. 263-91, doi.org/10.1177/0951692890002003002.

Sanderson, I 2009, 'Intelligent policy making for a complex world: Pragmatism, evidence and learning', Political Studies, vol. 57, no. 4, pp. 699-719, doi.org/ 10.1111/j.1467-9248.2009.00791.x.

Savigny, H 2019, 'The violence of impact: Unpacking relations between gender, media and politics', Political Studies Review, vol. 18, no. 2, doi.org/ $10.1177 / 1478929918819212$.

Schneider, A, Ingram, H \& DeLeon, P 2014, 'Democratic policy design: Social construction of target populations' in P Sabatier \& C Weible (eds), Theories of the policy process, 3rd edn, Westview Press, Boulder, CO.

Shanahan, E, Jones, M, McBeth, M \& Radaelli, C 2018, 'The narrative policy framework', in C Weible \& P Sabatier (eds), Theories of the policy process, 4th edn, Westview, Chicago, IL, doi.org/10.4324/9780429494284-6.

Simon, H 1976, Administrative behavior, 3rd edn, Macmillan, London, UK.

Sloman, S \& Fernbach, P 2017, The knowledge illusion: Why we never think alone, Penguin, London, UK.

Stewart, J \& Ayres, R 2001, 'Systems theory and policy practice: An exploration', Policy Sciences, vol. 34, no. 1, pp. 79-94, doi.org/10.1023/A:1010334804878.

Topp, L, Mair, D, Smillie, L \& Cairney, P 2018, 'Knowledge management for policy impact: The case of the European Commission's Joint Research Centre', Palgrave Communications, vol. 4, no. 87, doi.org/10.1057/s41599-018-0166-9. 
This text is taken from Learning Policy, Doing Policy: Interactions Between Public Policy Theory, Practice and Teaching, edited by Trish Mercer, Russell Ayres, Brian Head and John Wanna, published 2021 by ANU Press, The Australian National University, Canberra, Australia.

doi.org/10.22459/LPDP.2021.13 